\title{
Innovative Approach for IBS Vendor Selection Problem
}

\author{
Mohd Faizal Omar ${ }^{1, a}$, Mohd Nasrun Mohd Nawi ${ }^{2}$, Adi Irfan Che-Ani ${ }^{2}$, Nor Intan Saniah Sulaiman ${ }^{3}$ and \\ Kai Chen $\mathrm{Goh}^{4}$ \\ ${ }^{1}$ School of Quantitative Sciences, Universiti Utara Malaysia, 06010 Sintok, Kedah, Malaysia \\ ${ }^{2}$ School of Technology Management and Logistics, Universiti Utara Malaysia, 06010 Sintok, Kedah, Malaysia \\ ${ }^{3}$ Pusat Citra Universiti, Universiti Kebangsaan Malaysia, 43600 Bangi, Selangor, Malaysia \\ ${ }^{4}$ Faculty of Business and Technology Management, Universiti Tun Hussein Onn Malaysia, 86400 Batu Pahat, Johor, \\ Malaysia
}

\begin{abstract}
Supply chain management in Industrialised Building System (IBS) construction management has significantly determined the successful of company and project performance. Due to the wide variety of criteria and vendor available, the vendor selection process for a specific project needs is becoming more difficult. The need of decision aid for vendor selection in other areas is widely discussed in previous research. However, study on vendor selection for IBS project is largely neglected. Decision Support System (DSS) is proposed for this purpose. Yet, most of the DSS models are impractical since they are complicated and difficult for a layman such as project managers to use. Research indicates that the rapid development of ICT has highly potential towards simple and effective DSS. Thus, this paper highlights the importance and research approach for vendor selection in IBS project management. The study is based on Design Science Research Methodology with combination of case studies. It is anticipates that this study will yield an effective value-for-money decision making platform to manage vendor selection process.
\end{abstract}

\section{Introduction}

Construction industry can be considered as one of the foundation in Malaysia economy. Due to the high demand of housing and infrastructure, Malaysia has progressively moved toward industrialisation. However, the traditional approach in construction is not parallel with this objective. Traditional approach is always led to construction problem such as delay, overrun cost, redesign, and low quality of project outcome. Thus, new approach and method of construction is significant to fulfil the need of housing and infrastructure development. Thus, the introduction of new approach in Malaysia construction industry such as IBS has been considered as solution to the construction problems [1-3]. IBS is a construction system that is built using pre-fabricated components. The manufacturing of the components is systematically done using machine, formworks, and other forms of mechanical equipment. The components are manufactured off-site and once completed will be delivered to construction sites for assembly and erection. Building system can be classified with four main categories [3]:

\footnotetext{
${ }^{a}$ Corresponding author : mfaizal.omar@gmail.com
} 
a. Conventional building system

b. Cast-in-situ formwork system - table or tunnel formwork

c. Prefabricated system and

d. Composite system

IBS attempts to expedite the execution of the project by providing materials to be produced and constructed readily at the optimum time. The role of purchasing in supply management has been acknowledged as one of the foundation towards the successful of construction companies particularly in IBS construction project. Purchasing from the right vendor can enhances efficiency and competitiveness of IBS project. In prefabrication process, problems related to supplier such as material shortage or late delivery of material can negatively affect the IBS project process. Thus, there is a need to assess supplier's suitability for a specific IBS project. Client may need to consider supplier selection criteria such as quality, delivery, cost/price, financial, technology, etc. For IBS project, other related criteria might also be considered such as ISO certification, product development, flexibility, reliability, and management ability. This scenario increases the challenges to select the right and effective vendor. Effectiveness refers to vendor who can supply the right amount of materials or services at the right time, at right price and the right quality.

\section{Problem Statement}

One of the important processes during planning is vendor selection. Little attention is given in literature for IBS vendor selection problem. Based in the literature, there are multiple characteristics and criteria for industrialized building materials vendor to be considered in the project; such as delivery time, logistic issues, erection process, cost of purchasing etc. It imposed a complex scenario where it requires the right decision to be made before selecting an appropriate vendor. Poor decision in vendor selection would negatively affect not only company performance, yet affecting project performance as well. The performance of a few IBS vendor in Malaysian construction industry is an issue where poor decision were made in awarding the contract [5]. Thus, there is a need to aid decision making for IBS vendor selection. Till date, the decision making tools for this problem area is still far immature as most were ad-hoc decision. Thus, we aim to develop a Knowledge Based Multi Criteria Decision Support System for IBS Vendor Selection Problem. This study will attempt to fill the gap by developing a decision making framework and prototype to foster better decision making in IBS vendor selection.

\section{Related Work}

\subsection{Decision in supplier selection}

Vendor or Supplier selection has gained much attention from researchers in numerous fields worldwide. This is due to the importance of an effective supplier selection in supply chain management. For example, purchasing share would influence $40-80 \%$ of the total turnover of company [6]. In addition, in IBS construction management, supplier plays significantly importance towards project performance. An ineffective supply chain management would negatively affect project performance and led to construction problem such as delay, overrun time and, cost [7]. Furthermore, selection of the right vendor is crucial process due to the vagueness, imprecision of goal and constraint in decision process $[8,9]$. Due to the diversity of purchasing context, vendor selection also deals with tremendous criteria. For instance, a study has been conducted to compare the importance of supplier selection based on 110 research paper within 1991-2001 [9]. Their study revealed that there were some criteria were used consistently in vendor selection such as price, delivery, quality, production facilities and capacity, technical capability, geographical location, management, reputation and position in industry and, financial position. Other study also mentioned that criteria such as reliability, flexibility, consistency and long term relationship were also used 
frequently in other field [21]. However, in recent years, the new criteria emerge such as e-transaction ability [10], integrity, professionalism, commitment, economic, political situation [8], and environmental and social criteria [11]. The increasing of criteria in vendor selection has increase the complexity for this problem. As a result, various analytical techniques has been proposed. Previous research categorize vendor selection method into two groups i.e. single model and integrated model (Figure 1).

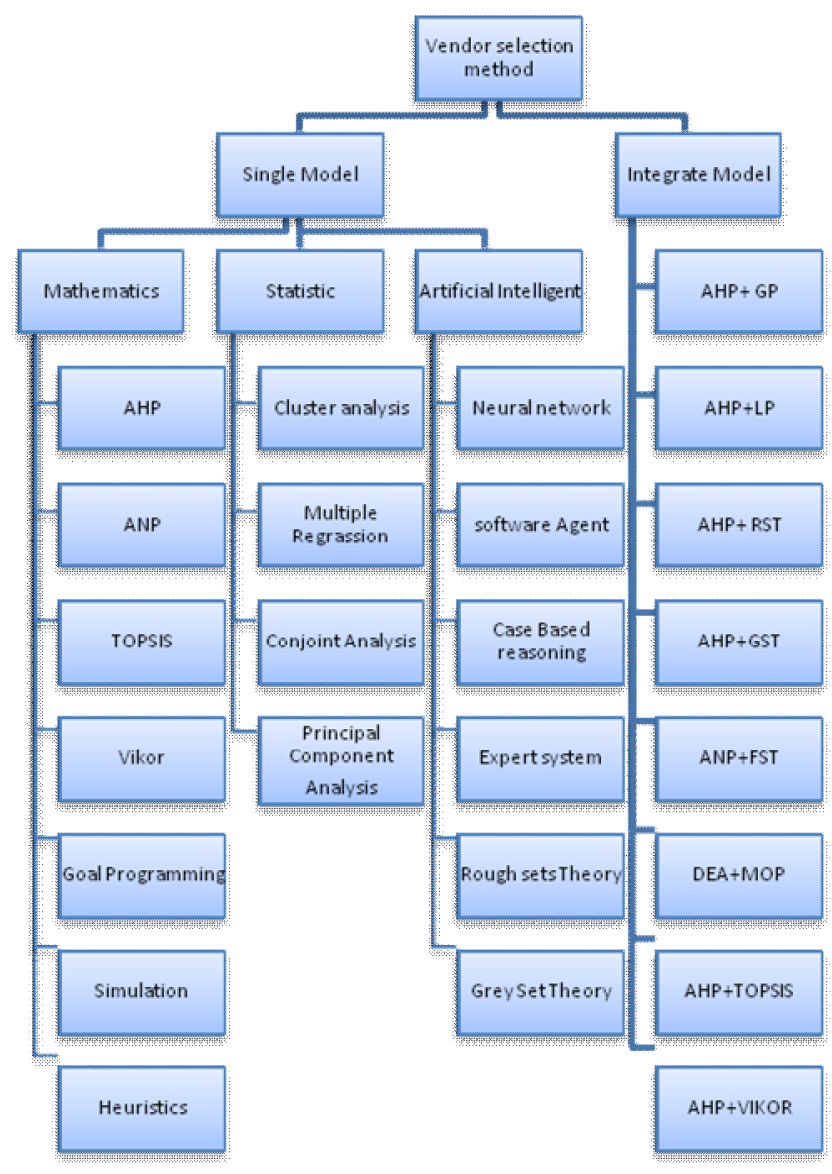

Figure 1. Method in supplier selection [12].

The above figure shows that Multi Attributes Decision Making (MADM) technique such as AHP, ANP, DEA, TOPSIS and, VIKOR dominates and capable of dealing with vendor selection problem. Thus, in order to enhance the vendor selection in IBS project management, we propose the integration of MADM method and DSS to be carried out.

\subsection{Decision support system and applications in construction project management}

DSS are computer programs that aid users in problem solving or decision-making environment. The system has detailed knowledge, data, models, algorithms, user interfaces, and control mechanisms to support a specific decision problem [13]. They are especially valuable in situations in which the amount of available information is prohibitive for the intuition of an unaided human decision maker. Furthermore, DSS can aid human cognitive deficiencies by integrating various sources of information, providing intelligent access to relevant knowledge, and aiding the process of structuring decisions. A 
lot of research on DSS in planning has been conducted to date in construction management [14-16]. However, most of the models are impractical since they are complicated and difficult for a layman such as project managers to use.

It is desirable to suppress those complexities in the models by an advanced DSS which can offer simple, effective and efficient tools towards better decision making. Some researchers only concentrate on model development and discards important computer science fundamentals, e.g. software engineering, information management and human-centred computing [14, 16, 17]. Some researchers have attempted to adopt computing essence in their model development [18]. However, they often imposed incorrect terms which led to erroneous concepts of software development modelling [19]. As a result, most of the models and methods are not being used or have limited impact for real-world decision making [20]. Nowadays, the trend of the cutting edge technology in ICT on cloud computing. The technology was named after the representation as a cloud, often described on a graphic representation of a network. Its concept on a large scale implies the use of the Internet in order to allow those interested to access virtual resources through which users can manage and control the services they have acquired. Thus, our proposed DSS will leverage the features in cloud technology to support mathematical approach for vendor selection problem In IBS project.

\section{Methodology}

Driven by the motivation and research objectives, Design Science Research Methodology (DSRM) will be utilised. Considering its capabilities to address issues pertaining to the design and development of an IT artefact, DSRM is well suited for the research involving system development. DSRM can also be used with case study approach in order to understand certain event or phenomena in depth [21]. In this research, we attempt to utilise a mix of case studies technique as strategy to demonstrates and develop DSS. Case study is chosen as a method to justify and validate the IT artefact. Hence, two case studies and software development process will be performed. Multiple of case study can enhance the development and validation of research rather than single case study. The descriptions of few main research activities are as follows.

\subsection{Case study 1: Requirement gathering for DSS}

The purpose of this activity is to deeply understand the requirements needed to develop DSS for a MCDM problem. Data will be collected through literature review. This phase is divided into three sub activities i.e. requirement elicitation, requirement analysis and System Design. The process in Case Study 1 mainly focuses on the aspect of Requirement Engineering. It concerned on the identification of the goals to be achieved by the envisioned system, the operationalisation of such goals into services and constraints, and the assignment of responsibilities for the resulting requirements to agents such as humans, devices, and software. There are six main categories of requirements that should be addressed which consist of (1) individual functionality, (2) business flow, (3) data, formats and information needs, (4) systems with other interfaces, (5) user interfaces, and (6) other constraints such as performance, reliability, and security

Requirements of DSS will be further analysed by using Case Study technique. To demonstrate a generic DSS architecture, it is proposed that a paper based decision modelling is conducted for vendor selection problem. A real case of IBS vendor selection problem in Malaysian construction industry will be selected to illustrate the modelling technique. As a result, mathematical decision model will be developed and validated by decision makers.

\subsection{DSS development}

Based on the previous software requirement in Case 1, DSS is proposed to incorporate model management, database and user interface. 


\subsection{Case study 2: Usability evaluation and validation of DSS}

Case Study 2 focuses on the evaluation of DSS for IBS vendor selection by decision makers. In this phase, the current practice result will be compared to DSS prototype output. Then a usability testing will be performed to assess its usability and utility. A set of heuristics questionnaire will be established. This iterative process will be followed by unstructured interview to capture stakeholder and enable them to "think aloud". The DSS prototype will be revised based on experts recommendations. Figure 2 below illustrates the conceptual concept of proposed DSS as mentioned in case 1 and 2 above.

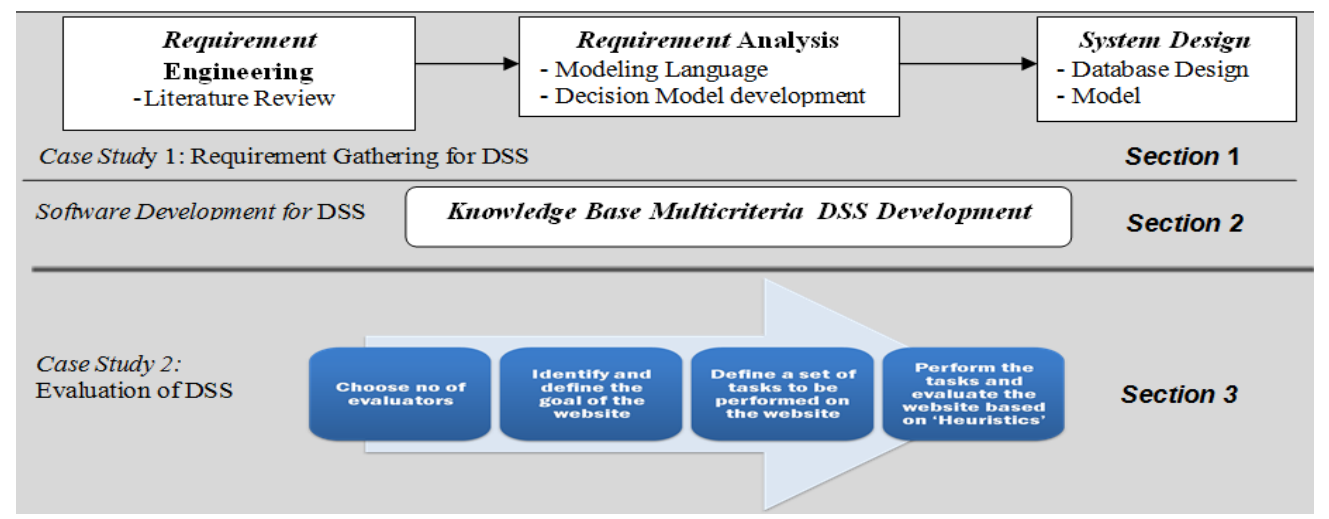

Figure 2. Conceptual framework for the proposed DSS.

\section{Discussion and Conclusion}

Vendor selection has been addressed as foundation towards an effective supply chain in numerous fields including construction. In recent years, the role of vendor selection has gained much attention. In Malaysian Construction Industry particularly for IBS, supplier/manufacture is one of the main project stakeholders who determined the successful of project. This is because IBS project is based on prefabrications method. Any disruption in supply chain such as material shortage or delay can automatically affect project process. In addition, issues regarding poor vendor performance are also raised. Hence, there is a need to select the right vendor to expedite the execution of the project by providing the materials for the project to be produced and constructed readily at the optimum time. Our study aims to develop knowledge base multi-criteria Decision Support System to profile and select the right IBS vendor to cater the need of Malaysian construction industry. Driven by the motivation and research aims, this study will base on case study and DSRM. Real case projects will be used to demonstrate the decision making framework. The data collection will include documental analysis and interviews with stakeholders. On the other hand, the implementation process involves the design of vendor profiling, implementation and evaluation of cloud based multi-criteria DSS. Unlike other DSS implementation in the literature, this DSS toolkit will be developed by using the latest cloud computing technology to solve IBS vendor selection in an innovative way. The artefact can be generalized to solve other type of multi criteria decision making problem which potentially foster a better quality, value-for-money and transparent decision making process.

\section{Acknowledgment}

The authors gratefully acknowledge the support by the Ministry of Education Malaysia for providing the funding under Research Acculturation Collaborative Effort (RACE). We also thank the contribution by other members in Construction Research Group and Analytical Minds CoE in UUM. 


\section{References}

[1] B. López-Mesa, Á. Pitarch, A. Tomás and T. Gallego, Comparison of environmental impacts of building structures with in situ cast floors and with precast concrete floors, Build. Environ., 44(4), 699-712, (2009).

[2] L. Jaillon, C.S. Poon and Y.H. Chiang, Quantifying the waste reduction potential of using prefabrication in building construction in Hong Kong, Waste Manag., 29(1), 309-320, (2009).

[3] Y.F. Badir, M.R.A. Kadir and A.H. Hashim, Industrialized building systems construction in Malaysia, J. Arhit. Eng., 8(1), 19-23, (2002).

[4] A. Cox, Power, value and SCM, Supply Chain Management, 4(4), 167-175, (1999).

[5] S.A.A.H.S.S. Hassim and M.S. Jaafar, The contractor perception towers Industrialised building system risk in construction projects in Malaysia, Am. J. Appl. Sci., 6, 937-942, (2009) .

[6] P.S. Tan, S.S.G. Lee and A.E.S. Goh, Multi-criteria decision techniques for context-aware B2B collaboration in supply chains, Decis. Support Syst., 52(4), 779-789, (2012).

[7] M.N.M. Nawi, A. Lee, M.N.A. Azman and K.A.M. Kamar, Fragmentation issue in Malaysia industrialised building system (IBS) project, J. Eng. Sience Technol., 9(1), 97-106, (2014).

[8] S. Thiruchelvam and J.E. Tookey, Evolving trends of supplier selection criteria and methods, Int. J. Automot. Mech. Eng., 4(1), 437-454, (2011).

[9] S.H. Cheraghi, M. Dadashzadeh and M. Subramanian, For supplier selection: An update, J. Appl. Bus. Res., 20(2), 91-108, (2004).

[10]A.K. Kar and A.K. Pani, Exploring the importance of different supplier selection criteria, Manag. Res. Rev., 37(1), 89-105, (2014).

[11]B.A. Ozturk and F. Ozcelik, Sustainable supplier selection with a fuzzy multi-criteria decision making method based on triple bottom line, 5(3), 129,147, (2014).

[12]K. Mukherjee, Supplier selection criteria and method: past, present and future, Int. Oper. Res., 39-44, (2014).

[13]H.K. Bhargava and C. Tettelbach, A web-based decision support system for waste disposal and recycling, Comput. Environ. Urban Syst., 21(1), 47-65, (1997).

[14]I.M. Mahdi, A multi-criteria approach to contractor selection, Eng. Constr. Archit. Manag., 9(1), 29-37, (2002).

[15]C. Kahraman, U. Cebeci and Z. Ulukan, Multi-criteria supplier selection using fuzzy AHP, Logist. Inf. Manag.,16(6), 382-394, (2003).

[16]A. Shapira and M. Goldenberg, AHP-based equipment selection model for construction projects, J. Constr. Eng. Manag., 131(12), 1263-1273, (2005).

[17]R. Manoharan, Subcontractor selection method using analythic hierarchy process, Universiti Teknology Malaysia, (2005).

[18]A.K. McCowan and S. Mohamed, A classification of Decision Support System for the analysis and evaluation of concession project investment, J. Financ. Manag. Prop. Constr., 7(2), 127-137, (2002).

[19]M.F. Omar, B. Trigunarsyah and J. Wong, The state of art of decision support system development: Progress of requirement engineering in construction, International Building and Infrastructure Technology Conference, (2011).

[20]Q. Tian, J. Ma and O. Liu, A hybrid knowledge and model system for R\&D project selection, Expert Syst. Appl., 23(3), 265-271, (2002).

[21]C.A. Weber, J.R. Current and W.C. Benton, Vendor selection criteria and methods, Eur. J. Oper. Res., 50(1), 2-18, (1991 